\title{
Environmental impacts and benefits of marine floating solar
}

\author{
Tara Hooper ${ }^{\star 1}$, Alona Armstrong ${ }^{2,3}$, and Brigitte Vlaswinkel ${ }^{4}$
}

* corresponding author: tara.hooper@plymouth.ac.uk

1. School of Biological and Marine Sciences, University of Plymouth, Drake Circus, Plymouth, PL4

8AA, UK.

2. Lancaster Environment Centre, Lancaster University, Lancaster, LA1 4YQ, UK.

${ }^{3}$ Energy Lancaster, Lancaster University, Lancaster, LA1 4YF

${ }^{4}$ Oceans of Energy, Valkenburg Airport, Wassenaarseweg 75, 2223LA Katwijk, The Netherlands

\begin{abstract}
Deployment of floating solar photovoltaic installations (floatovoltaics) is advancing, with various designs beginning to appear in a range of marine environments. Insight from freshwater floatovoltaics is not readily transferable offshore, and so lessons from other marine energy infrastructure are used to highlight how the marine environment may impact floatovoltaics, how the floatovoltaics impact the environment (both positively and negatively) and the likely societal response. It becomes clear that research to understand the environmental and societal implications of floating solar in the marine environment must proceed in parallel with investigations of the technical and economic feasibility.
\end{abstract}

\section{Introduction}

The deployment of floating solar photovoltaic arrays (floatovoltaics) in freshwater environments has risen exponentially, and now installations are beginning to appear at sea (SERIS, 2019). Marine demonstrations have occurred in shallow tropical lagoons (Maldives), deep, protected fjords (Norway), the rough North Sea (The Netherlands), and nearshore in the Persian Gulf (Dubai). As a consequence, marine designs vary significantly: circular structures with central photovoltaic panels on a thin hydro-elastic membrane; individual square pontoons (Fig 1a); rectangular, closely interconnected, rigid modules (Fig 1b); or small, light structures, each supporting individual photovoltaic panel(s) (Fig 1c).

(a)

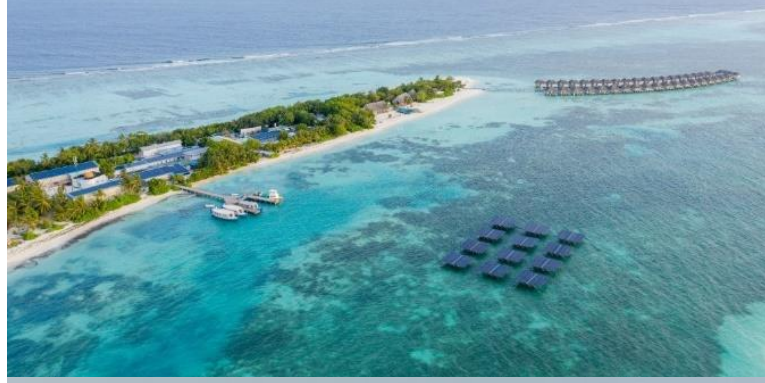

(c)

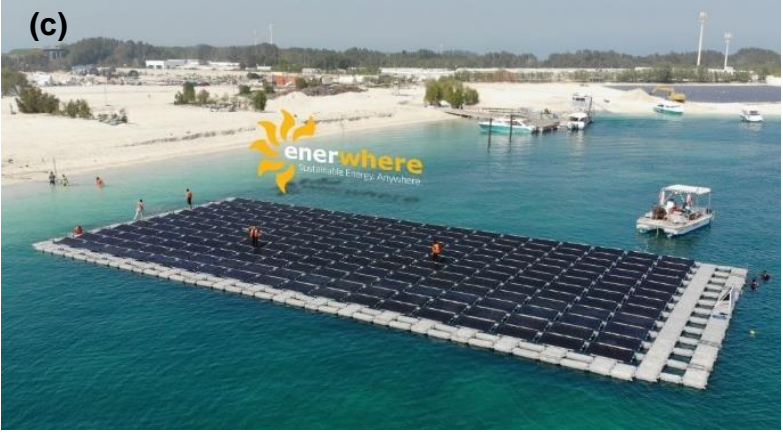

(b)

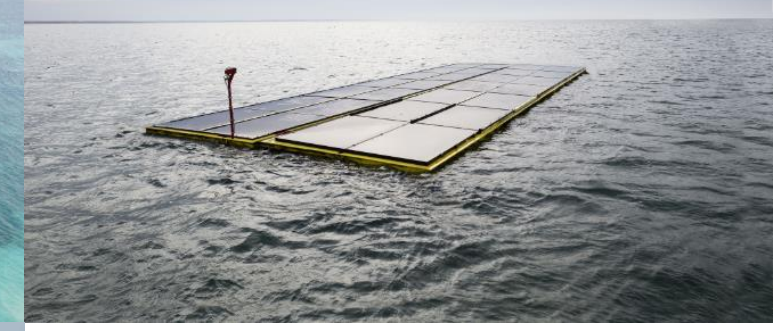

Figure 1. (a) Swimsol's floating SolarSea ${ }^{\mathrm{TM}}$ platforms in the Maldives (photo provided by Swimsol).

(b) Oceans of Energy floating solar array in the Dutch North Sea (photo provided by Oceans of Energy).

(c) Enerwhere's floating solar on sea water in Abu Dhabi, UAE (photo provided by enerwhere) 
Knowledge of floatovoltaic impacts on inland waters is emerging, but insight is not readily transferable to marine environments as they are unbounded, tidal, saline, highly ecologically diverse and, generally, experience stronger winds, waves and currents. Increased understanding of the interactions between emerging floatovoltaic designs and the marine environment is therefore required. In the absence of direct field studies, experience with other man-made structures at sea (particularly other offshore energy platforms) can serve as a proxy to infer probable impacts and highlight research needs. This Brief Note provides an introduction to the main areas of environmental impact that need to be considered for marine-based floatovoltaic applications.

\section{Ecosystem effects on marine floatovoltaic systems}

Simultations suggest that photovoltaic system performance at sea can increase by up to $13 \%$ compared to land-based systems due to natural cooling (Golroodbari and Sark, 2020). However, the harsh marine environment, and its implications for the reliability of components and devices, is a major engineering challenge for ocean-based energy (Theis, 2012). Consequently, marine floatovoltaic design will need to take account of how the environment will affect system integrity and performance. Arguably the principal ecosystem impact is the rapid and extensive colonisation of structures by fouling organisms. For example, 115 taxa were found on a floating wave energy converter, and the mass of biofouling at the waterline exceeded $2 \mathrm{~kg} \mathrm{~m}^{-2}$ (Nall et al., 2017). Biofouling also roughens the surface of the structure, increasing drag coefficients and otherwise affecting hydrodynamic loading (Jusoh and Wolfram, 1996). There are implications for thermal management, as the dissipation of heat from cables and other components may be affected by the growth of marine organisms (Narayanaswamy, 2013). Biofouling is also likely to enhance corrosion and corrosion fatigue; modelling suggests that fouling could decrease the fatigue life of wave energy mooring lines by 20\% (Yang et al., 2017). Fouling also increases maintenance costs (Edyvean, 1987). Moreover, colonisation of the photovoltaic surfaces may affect rates of power absorption; biofouling extends into the splash zone and can affect light transmittance even at low biomass through the occurrence of thin films of organisms that are strong absorbers of light (Harris et al., 2013). Much existing learning about the presence and treatment of biofouling is transferable to floatovoltaics. Key knowledge gaps remain, however, particularly around the implications of fouling for novel materials (Loxton et al., 2017) and the implications of salt deposits on generation. The complexity of the biofouling issue requires sitespecific testing to provide accurate risk assessment (Blair et al., 2014), which is pivotal given the range of marine environments floatovoltaics are deployed within.

\section{Impact of marine floatovoltaics on ecosystems}

The impact of marine floatovoltaics on the ecosystem will depend on the project design, as well as on environmental variables such as geography, water depth, distance to shore and local hydro- and oceanographical conditions. A first study modelling the effects of large-scale marine floatovoltaics in a temperate, shallow coastal sea illustrates negligible effects on net primary production and also reduced turbidity, which is beneficial for light availability underneath the platforms (Karpouzoglou et al., 2020). Early studies suggest freshwater floatovoltaics increase water quality by reducing algal blooms (Jones \& Armstrong, 2018; Sahu et al., 2016) and decrease evaporation rate, a notable cobenefit in areas of water scarcity (Santafe et al., 2014; da Silva and Branco, 2018). Negative environmental effects include anchoring and cable impacts on the substrate, disturbance during installation including sediment resuspension, blocking sunlight penetration, and electromagnetic field effects (Sahu et al., 2016; Pimental da Silva \& Branco, 2018). These risks also apply in the marine environment. Shading and sediment resuspension are of particular concern for coral reefs and seagrass, which require sunlight for growth (Rogers, 1990; Benham et al., 2016). Furthermore, tidal changes in water depths may result in extended periods during which slack mooring cables interact with the seabed. Any dragging of the cables as the floating structure moves with the wind and waves will cause scour. This is again of particular concern for seagrass beds, and also for the carbon stocks stored within their sediments (Serrano et al., 2016). Careful project design is important to mitigate detrimental impacts.

There are general risks associated with new installations, including the spread of invasive species; modelling suggests that offshore wind structures may act as vectors for the widespread distribution of both intertidal and pelagic species (Adams et al., 2014; Jansen et al., 2013). Risks are heightened if marine energy infrastructure is 'wet-towed' from harbour to the deployment site, as ports are often highly contaminated with non-native species (Loxton et al., 2017). The introduction of new infrastructure into areas of otherwise soft sediment will alter the biodiversity at the site more generally. Species that inhabit hard substrate are different to those in sedimentary seabeds, and surface 
piercing structures will introduce species adapted for the shoreline into areas previously inhabited by those found only in fully marine conditions (Kerckhof et al., 2009, 2011).

Not all potential environmental implications are negative, however. Offshore energy infrastructure provides new substrate for species to settle on, and so functions as an artificial reef (Kogan, 2006; Sherwood et al., 2016). These small organisms that attach to structures form the base of food webs, which, together with the shelter offered by energy infrastructure, create environments attractive to larger and more mobile species such as crab, lobster and fish (Hooper et al., 2018). Species use the offshore structures as stepping stones to colonise larger areas or as nursery grounds, which create spill-over effects to the surrounding areas. Most studies to date have focussed on artificial reefs created by the foundations and scour protection around offshore wind farms and oil and gas platforms (and hence on species that live close to the seabed). However, floating structures are also widely utilised by fish that inhabit the wider water column (Dempster and Taquet, 2004). Understanding, and enhancing, positive environmental effects at the design stage would also align the industry with the wider policy direction for marine renewable energy: nature-inclusive designs for offshore wind farms are now mandated in parts of Europe (Bureau Waardenburg, 2020).

\section{Public perception}

Offshore energy infrastructure, particularly nearshore, attracts opposition from the public. Concerns about environmental impacts are a key factor in likely public opposition, and can outweigh the potential benefits (such as local job creation) in shaping attitudes (Hooper et al., 2020). These concerns include perceived impacts on wildlife, but also direct impacts on people through their use of the environment. Visual impact is known to be an issue for solar parks on land (Bevk \& Golobič, 2020) and for offshore wind developments (Voltaire \& Koutchade, 2020) and so is likely to be of concern for marine floatovoltaics, particularly in areas with high levels of recreation and tourism.

Artificial reef effects create opportunities for commercial and recreational fisheries to be co-located with energy devices potentially reducing conflict with other marine users; displacement of fishing activities is of particular concern as more marine space is utilised for marine renewable energy (Mackinson et al., 2006). Deploying floatovoltaics between offshore wind turbines is one mechanism for reducing the spatial footprint of offshore energy. The principle of shared marine spaces is extended in the concept of multi-use platforms, whereby common infrastructure is used for multiple activities, such as energy production and aquaculture (Schupp et al., 2019; Zheng et al., 2020). The potential of the use of marine floatovoltaics to support aquaculture is under investigation in projects such as the EU-funded UNITED programme.

Research on public attitudes, user conflicts and co-location for the marine energy sector has tended to focus on northern Europe and Canada, as the locations in which most offshore wind and tidal energy has been deployed to date (Hooper et al., 2020). Understanding of these issues in developing countries, which may be a specific target for floating solar given the flexibility in system size and lower cost, is less well advanced and requires particular attention.

\section{Conclusion}

Realising opportunities for marine floatovoltaics brings with it the need to understand a range of environmental implications; resolving the effects of biofouling on system performance is critical. Potential negative impacts of any installation on marine life need to be assessed comprehensively, particularly in highly vulnerable ecosystems such as coral reefs and seagrass. However, there is the opportunity for the sector to ensure, from the outset, that designs maximise positive environmental outcomes. Interactions with other marine users, and the factors that shape public opinion, need to be considered very early in project design. Opponents can be vocal, and initial impressions are going to be important in shaping the acceptability of any nascent marine solar industry. In summary, it is essential that research to understand the environmental and societal implications of floating solar in the marine environment proceeds in parallel with investigations of the technical and economic feasibility.

\section{Acknowledgments}

AA was supported by a NERC Industrial Innovation Fellowship (grant number: NE/R013489/1).

\section{References}


Adams, T., Miller, R., Aleynik, D. and Burrows, M. (2014). Offshore marine renewable energy devices as stepping stones across biogeographical boundaries. Journal of Applied Ecology, 51: 330-338.

Benham, C. F., Beavis, S. G., Hendry, R. A., \& Jackson, E. L. (2016). Growth effects of shading and sedimentation in two tropical seagrass species: Implications for port management and impact assessment. Marine pollution bulletin, 109(1), 461-470.

Bevk, T., \& Golobič, M. (2020). Contentious eye-catchers: Perceptions of landscapes changed by solar power plants in Slovenia. Renewable Energy, 152, 999-1010.

Blair, S., Roberts, D., Scantlebury, M. and Eden, B. 2014. The Potential Impacts of Biofouling on a Wave Energy Converter Using an Open Loop Seawater Power Take Off System. Prepared for Aquamarine Power. March 2014. https://s3-eu-west-1.amazonaws.com/media.newore.catapult/ app/uploads/2018/03/09084343/Biofouling-Literature-Review.pdf

Bureau Waardenburg. (2020). Options for biodiversity enhancement in offshore wind farms. Knowledge base for the implementation of the Rich North Sea Programme. Bureau Waardenburg Rapportnr.19- 0153. Bureau Waardenburg, Culemborg.

Dempster, T., \& Taquet, M. (2004). Fish aggregation device (FAD) research: gaps in current knowledge and future directions for ecological studies. Reviews in Fish Biology and Fisheries, 14(1), 21-42.

Edyvean, R. G. J. (1987). Biodeterioration problems of North Sea Oil and gas production-a review. International biodeterioration, 23(4), 199-231.

Golroodbari, S.Z. \& van Sark., W (2020). Simulation of performance differences between offshore and land-based photovoltaoic systems. Prog Photovolt Res Appl.1-14. DOI: 10.1002/pip.3276

Harris, L., Tozzi, S., Wiley, P., Young, C., Richardson, T. M. J., Clark, K., \& Trent, J. D. (2013). Potential impact of biofouling on the photobioreactors of the Offshore Membrane Enclosures for Growing Algae (OMEGA) system. Bioresource technology, 144, 420-428.

Hooper, T. C., Ashley, M. E., \& Austen, M. C. (2018). Capturing benefits: opportunities for the colocation of offshore energy and fisheries. In Offshore Energy and Marine Spatial Planning (Vol. 189, No. 213, pp. 189-213). Routledge in association with GSE Research.

Hooper, T., Hattam, C., Edwards-Jones, A., and Beaumont, N. 2020. Public perceptions of tidal energy: can you predict social acceptability across coastal communities in England? Marine Policy, 119. 104057

Janßen, H., C. B. Augustin, et al. (2013). Impact of secondary hard substrate on the distribution and abundance of Aurelia aurita in the western Baltic Sea. Marine Pollution Bulletin, 75(1-2): 224-234.

Jones I. \& Armstrong A. (2018) Investigating the impacts of floating solar on the water environment. PV Tech Power, 15, 60-63

Jusoh, I., \& Wolfram, J. (1996). Effects of marine growth and hydrodynamic loading on offshore structures. Jurnal Mekanikal, 1(1).

Karpouzoglou, T., Vlaswinkel, B., \& van der Molen, J. (2020). Effects of large-scale floating (solar photovoltaic) platforms on hydrodynamics and primary production in a coastal sea from a water column model. Ocean Science, 16(1), 195-208.

Kerckhof, F., Degraer, S., Norro, A., \& Rumes, B. (2011). Offshore intertidal hard substrata: a new habitat promoting non-indigenous species in the Southern North Sea: an exploratory study. Offshore wind farms in the Belgian Part of the North Sea: Selected findings from the baseline and targeted monitoring. Royal Belgian Institute of Natural Sciences, Management Unit of the North Sea Mathematical Models, Marine ecosystem management unit, Brussels, 27-37. 
Kerckhof, F., Norro, A., Jacques, T., \& Degraer, S. (2009). Early colonisation of a concrete offshore windmill foundation by marine biofouling on the Thornton Bank (southern North Sea). Offshore wind farms in the Belgian part of the North Sea: State of the art after two years of environmental monitoring, 39-51.

Kogan, I., Paull, C. K., Kuhnz, L. A., Burton, E. J., Von Thun, S., Greene, H. G., \& Barry, J. P. (2006). ATOC/Pioneer Seamount cable after 8 years on the seafloor: Observations, environmental impact. Continental Shelf Research, 26(6), 771-787.

Loxton, J., Macleod, A. K., Nall, C. R., McCollin, T., Machado, I., Simas, T., ... \& Miller, R. G. (2017). Setting an agenda for biofouling research for the marine renewable energy industry. International journal of marine energy, 19, 292-303.

Mackinson, S., Curtis, H., Brown, R., McTaggart, K., Taylor, N., Neville, S., \& Rogers, S. (2006). A report on the perceptions of the fishing industry into the potential socio-economic impacts of offshore wind energy developments on their work patterns and income. Science Series Technical ReportCentre for Environment Fisheries and Aquaculture Science, 133.

Nall, C. R., Schläppy, M. L., \& Guerin, A. J. (2017). Characterisation of the biofouling community on a floating wave energy device. Biofouling, 33(5), 379-396.

Narayanaswamy, V. (2013). Review of challenges in reliable electric power delivery to remote deep water enhanced oil recovery systems. Applied Ocean Research, 43, 53-67.

Rogers, C. S. (1990). Responses of coral reefs and reef organisms to sedimentation. Marine ecology progress series. Oldendorf, 62(1), 185-202.

Sahu, A., Yadav, N., \& Sudhakar, K. (2016). Floating photovoltaic power plant: A review. Renewable and sustainable energy reviews, 66, 815-824.

Santafé, M. R., Soler, J. B. T., Romero, F. J. S., Gisbert, P. S. F., Gozálvez, J. J. F., \& Gisbert, C. M. F. (2014). Theoretical and experimental analysis of a floating photovoltaic cover for water irrigation reservoirs. Energy, 67, 246-255.

Schupp, M. F., Bocci, M., Depellegrin, D., Kafas, A., Kyriazi, Z., Lukic, I., ... \& Buck, B. H. (2019). Towards a common understanding of ocean multi-use. Frontiers in Marine Science, 6, 165.

SERIS. (2019). Where Sun meets Water. Floating Solar Market Report. prepared by the Solar Energy Research Institute of Singapore (SERIS) at the National University of Singapore (NUS), under contract from the World Bank. Washington, The World Bank.

https://openknowledge.worldbank.org/handle/10986/31880

Serrano, O., Ruhon, R., Lavery, P. S., Kendrick, G. A., Hickey, S., Masqué, P., ... \& Duarte, C. M. (2016). Impact of mooring activities on carbon stocks in seagrass meadows. Scientific reports, 6(1), 110.

Sherwood, J., Chidgey, S., Crockett, P., Gwyther, D., Ho, P., Stewart, S., ... \& Williams, A. (2016). Installation and operational effects of a HVDC submarine cable in a continental shelf setting: Bass Strait, Australia. Journal of Ocean Engineering and Science, 1(4), 337-353.

da Silva, G. D. P., \& Branco, D. A. C. (2018). Is floating photovoltaic better than conventional photovoltaic? Assessing environmental impacts. Impact Assessment and Project Appraisal, 36(5), 390-400.

Thies, P. R. (2012). Advancing reliability information for wave energy converters.PhD Thesis, University of Exeter. 
Voltaire, L., \& Koutchade, O. P. (2020). Public acceptance of and heterogeneity in behavioral beach trip responses to offshore wind farm development in Catalonia (Spain). Resource and Energy Economics, 60, 101152.

Yang, S. H., Ringsberg, J. W., Johnson, E., \& Hu, Z. (2017). Biofouling on mooring lines and power cables used in wave energy converter systems-analysis of fatigue life and energy performance. Applied Ocean Research, 65, 166-177.

Zheng, X., Zheng, H., Lei, Y., Li, Y., \& Li, W. (2020). An offshore floating wind-solar-aquaculture system: concept design and extreme response in survival conditions. Energies, 13(3), 604. 